CLINICAL STUDY

\title{
Prednisone affects inflammation, glucose tolerance, and bone turnover within hours of treatment in healthy individuals
}

Eunkyung Kauh, Lori Mixson, Marie-Pierre Malice, Sofie Mesens ${ }^{1}$, Steven Ramael ${ }^{1}$, Joanne Burke, Tom Reynders ${ }^{2}$, Kristien Van Dyck ${ }^{2}$, Chan Beals, Elizabeth Rosenberg and Marcella Ruddy

Merck Sharp and Dohme Corp., Whitehouse Station, New Jersey 08889, USA, ${ }^{1}$ SGS/Biopharma, 2060 Antwerp, Belgium and ${ }^{2}$ MSD Europe, 1200 Brussels, Belgium

(Correspondence should be addressed to E Kauh who is now at Merck Sharp and Dohme Corp., UG4D-34, PO Box 1000, North Wales, Pennsylvania 19454-1099, USA; Email: eunkyung_kauh@merck.com)

\begin{abstract}
Objective: Use of glucocorticoids for anti-inflammatory efficacy is limited by their side effects. This study examined, in the same individuals, prednisone's acute, dose-dependent effects on inflammation as well as biomarkers of glucose regulation and bone homeostasis.

Design: In this randomized, double-blind, parallel-design trial of healthy adults demonstrating cutaneous allergen-induced hypersensitivity, patients received placebo or prednisone 10, 25 or $60 \mathrm{mg}$ daily for 7 days.

Methods: Effects on peripheral white blood cell (WBC) count, ex vivo whole blood lipopolysaccharide (LPS)-stimulated TNF- $\alpha$ release and response to cutaneous allergen challenge were assessed concurrently with biomarkers for glucose tolerance and bone turnover.

Results: Differential peripheral WBC counts changed significantly within hours of prednisone administration. $E x$ vivo, LPS-stimulated TNF- $\alpha$ was significantly reduced by all prednisone doses on days 1 and 7 . The late phase cutaneous allergen reaction was significantly reduced with prednisone $60 \mathrm{mg}$ vs placebo on days 1 and 7 . Oral glucose tolerance tests revealed significant increases in glycaemic excursion on days 1 and 7, whereas increases in insulin and C-peptide excursions were more notable on day 7 with all doses of prednisone. The bone formation markers osteocalcin, and procollagen I N- and $\mathrm{C}$-terminal peptides decreased significantly on days 1 and 7 vs placebo.

Conclusions: In healthy young adults after single doses as low as $10 \mathrm{mg}$, prednisone treatment has significant effects on glucose tolerance and bone formation markers within hours of treatment, in parallel with anti-inflammatory effects.
\end{abstract}

European Journal of Endocrinology 166 459-467

\section{Introduction}

The anti-inflammatory effects of glucocorticoids (GCs) have proven extremely valuable in the treatment of diseases such as asthma, arthritis and transplant organ rejection. However, the side effects following prolonged use of GCs at pharmacologic concentrations limit both their full dose-range potential and long-term use (1). Two of the most common and debilitating adverse effects of GC therapy are glucose intolerance that can lead to or exacerbate pre-existing diabetes and effects on bone that over time can develop into GC-induced osteoporosis.

GC treatment results in numerous effects influencing glucose metabolism $(1,2,3)$. It is well known that GCs inhibit insulin secretion, induce triglyceride breakdown in adipose tissue, decrease insulin-mediated glucose uptake in skeletal muscle and increase hepatic glucose production by increasing gluconeogenesis. It is not surprising that GC-induced diabetes is commonly encountered clinically and has been documented in several studies of patients with organ transplantation or renal disease, with an incidence ranging from 2 to $53 \%$ $(4,5)$. Changes in glucose tolerance have been detected by oral glucose tolerance test (OGTT) within hours of treatment (6). However, studies examining the dosedependent effects of GCs and, in particular, dosedependent single dose effects have not been performed.

GC therapy is also associated with accelerated decline in bone density and an increase in fractures (reviewed in $(7,8))$. GCs reduce osteoblast function and replication as well as increase osteoblast apoptosis $(1,8,9,10)$. Although the specific mechanism by which GCs interfere with osteoblast function remains unclear, reductions in bone formation markers have been reported to occur within days of treatment with prednisone $(11,12,13$, $14,15)$, and increases of about two- or three-fold in the relative risk of hip and vertebral fractures in patients receiving GCs have been reported $(16,17)$.

Although the most severe adverse effects associated with GC treatment generally occur in patients 
undergoing chronic treatment with high doses, the onset of changes in glucose tolerance and bone turnover occurs soon after treatment initiation, as described above. Given the significant therapeutic value of GCs, there has been intense effort to identify dissociated GC receptor agonists that possess the anti-inflammatory properties of classic GC receptor agonists, such as prednisolone and dexamethasone, without inducing the undesirable side effects (reviewed in (18)). A better understanding of the time course relationship between GC dose and biomarkers of both efficacy and adverse effects in the same population should facilitate this search. The current investigation, in which healthy young individuals were treated with the commonly prescribed oral GC prednisone, was conducted to identify biological markers of inflammation, glucose tolerance or bone turnover which demonstrate acute, dose-dependent relationships. To our knowledge, this is the first published study comparing the time- and dosedependent anti-inflammatory effects of prednisone with adverse effects in the same individuals.

\section{Subjects and methods}

\section{Subjects}

Caucasian, non-Hispanic men or women (neither pregnant nor lactating) aged $18-50$ years $(n=48)$ were recruited at SGS Life Science Services (Antwerp, Belgium). The main inclusion criteria were body mass index from $>20$ to $30 \mathrm{~kg} / \mathrm{m}^{2}$, hypersensitivity to one of two commercial antigen preparations (allergen screening reactions to a standard skin prick test of mixed grass or dust mite antigen with a wheal $\geq 3 \mathrm{~mm}$ at $15 \mathrm{~min}$ ), a $\geq 10 \mathrm{~mm}$ acute wheal at $15 \mathrm{~min}$ and a cutaneous late phase reaction (LPR) at $\sim 8 \mathrm{~h}$ postchallenge with an allergen test (described below under Anti-inflammatory effects) on the volar forearm, and a state of general good health. Principal exclusion criteria included a history of glucose intolerance, adrenal impairment and significant illnesses or abnormal laboratory evaluations. The study was conducted in accordance with principles of Good Clinical Practice and was approved by the appropriate institutional review boards and regulatory agencies. All subjects provided written informed consent.

During the course of the study, patients were required to refrain from excessive sun exposure, strenuous physical activity, use of lotion on the arms or back and use of any prescription or non-prescription medicine.

\section{Study design and treatment}

This was a randomized, double-blind, placebo-controlled, parallel group, 7-day study (Study Protocol 059) with varying doses of prednisone. Enrolled patients were randomized (allocation stratified by allergen type: dust mite or mixed grass pollen) in a double-blind fashion to four groups: oral prednisone 10, 25 or $60 \mathrm{mg}$, or placebo daily for 7 days. All patients received an equal number of pills containing $5 \mathrm{mg}$ prednisone (GALENpharma, GMBH, Kiel, Germany) or matching placebo. At baseline (7-14 days prior to day 1 ) and on days 1 and 7 , subjects fasted for at least $8 \mathrm{~h}$ prior to treatment and for about $8 \mathrm{~h}$ post-treatment.

\section{Anti-inflammatory effects}

The primary anti-inflammatory endpoint was the area under the curve $\left(\mathrm{AUC}_{2-8 \mathrm{~h}}\right)$ of the size of the LPR (i.e. skin erythema or induration, whichever was larger, surrounding the point of intra-dermal allergen injection) versus time. The LPR to the antigen was assessed at baseline and on days 1 and 7 . Allergen $(0.1 \mathrm{ml}$ at a concentration of 100 allergen units/ml of either the dust mite allergen Dermatophagoides pteronyssinus or Grass Pollen II, HAL Allergy BV, Haarlem, The Netherlands) was injected intradermally into the lower back flank, in a non-sun exposed area. At 2, 4, 6 and $8 \mathrm{~h}$ after the injection, the shape of the wheal surrounding the injection was traced onto scan tape. The area was assessed by scanning the image (software from Definiens Imaging $\mathrm{GmbH}$, Munich, Germany). To evaluate cellular infiltration of the LPR, skin-punch biopsies of 3-4 mm diameter, $\sim 1 \mathrm{~cm}$ from the injection site, were performed at baseline and $8 \mathrm{~h}$ post-treatment on day 7 . The best morphological sections $(5 \mu \mathrm{m}$, stained with haematoxylin and eosin) of each of four groups of four adjacent sections were used for counting eosinophils under $400 \times$ magnification.

Blood samples were taken pre-dose and at $8 \mathrm{~h}$ postdose on days 1 and 7 for measurement of ACTH, predose and at 5, 8 and $24 \mathrm{~h}$ post-dose on days 1 and 7 for total and differential white blood cell (WBC) counts, and at $8 \mathrm{~h}$ post-dose on days 1 and 7 for ex vivo analysis of whole blood lipopolysaccharide (LPS)-stimulated TNF- $\alpha$, as described (19). WBC counts were performed at the investigator site and TNF- $\alpha$ analysis was performed at the Merck Clinical Development Laboratory.

\section{Effects on glucose tolerance}

The primary endpoint for glucose tolerance was the 3-h glucose excursion during an $\operatorname{OGTT}(20,21)$ performed at baseline and $5 \mathrm{~h}$ post-treatment on days 1 and 7 at the clinical site. Briefly, subjects were instructed to consume $\geq 150 \mathrm{~g}$ carbohydrates/day for 3 days and then fast for $8 \mathrm{~h}$ on the evening prior to receiving their prescribed treatment. Peripheral blood samples were taken prior to the OGTT (time 0 of the OGTT). A standard $75 \mathrm{~g}$ oral glucose challenge was administered followed by peripheral blood sampling after 10, 20, 30, $60,75,120$ and $180 \mathrm{~min}$. Secondary endpoints included serum insulin and C-peptide excursions during the OGTT. 


\section{Effects on bone turnover}

The primary endpoint in the examination of bone turnover was serum concentration of the bone formation marker osteocalcin (Bioanalytical Research Corporation, Ghent, Belgium). Secondary endpoints included the serum concentrations of the bone formation markers procollagen I N- and C-terminal peptides (PINP and PICP) and the bone resorption marker N-telopeptide of type I collagen (NTX) (Quest Diagnostics Limited, Heston, UK). Serum concentrations of the bone formation marker Dikkopf-1 (Dkk-1) were also assessed (Merck Clinical Development Laboratory, Rahway, NJ, USA). Total Dkk-1 was detected in EDTA plasma using a human Dkk-1 kit (Assay Designs, Plymouth Meeting, PA, USA).

\section{Statistical analysis}

All subjects treated were included in the data analyses. All analyses were performed on data collected on days 1 and 7 of dosing using the change from baseline as the outcome measure. Treatment group comparisons were evaluated using a pre-specified analysis of covariance (ANCOVA) model with terms for allergen stratum as well as baseline and treatment. $\mathrm{LPR} \mathrm{AUC}_{2-8} \mathrm{~h}$ was $\log$ transformed prior to analysis and geometric mean percent changes from baseline were back-transformed for presentation of data. For the analysis of LPSstimulated ex vivo TNF- $\alpha$, the average monocyte levels at 5 and $8 \mathrm{~h}$ post-drug were also in the ANCOVA model.
For each outcome measure, the treatment effect (each dose of prednisone compared with placebo) was evaluated in a stepwise fashion, starting with the highest dose, until lack of significance was observed. The stepwise nature of this procedure controlled the error rate at 5\% with no formal adjustment for multiplicity required. No adjustment for multiplicity was performed for multiple testing on days 1 and 7 .

\section{Results}

In this randomized, double-blind, dose-ranging study of prednisone in healthy young adults, the 48 subjects enrolled were $60 \%$ male and had a mean age of 32 years. Baseline characteristics were not significantly different among treatment groups, and are shown in Table 1.

Serum ACTH was examined as a marker of GC treatment. As expected in patients receiving placebo, ACTH decreased in a physiologic manner during the course of the day, from $0800 \mathrm{~h}$ (just prior to treatment) to $1600 \mathrm{~h}$. On day 1 of treatment, highly statistically significant reductions $(P<0.001)$ in $\mathrm{ACTH}$ that exceeded the physiologic decreases observed with placebo were seen at all prednisone dose levels at $8 \mathrm{~h}$ post-dose. The increased reduction in ACTH over the course of the day was also seen for all doses of prednisone relative to placebo $(P<0.001)$ on day 7 . It should be noted that, in patients receiving the $60 \mathrm{mg}$

Table 1 Baseline characteristics. Data is presented as mean (s.D.) or as specified.

\begin{tabular}{|c|c|c|c|c|}
\hline & \multicolumn{4}{|c|}{ Treatment group } \\
\hline & \multirow[b]{2}{*}{ Placebo } & \multicolumn{3}{|c|}{ Pred } \\
\hline & & $10 \mathrm{mg}$ & $25 \mathrm{mg}$ & $60 \mathrm{mg}$ \\
\hline$n$ & 12 & 12 & 12 & 12 \\
\hline Male $n(\%)$ & $8(67)$ & $8(67)$ & $7(58)$ & $7(58)$ \\
\hline \multicolumn{5}{|l|}{ Stratification $n(\%)$} \\
\hline Dust mite allergen & $7(58)$ & $8(67)$ & $8(67)$ & $7(58)$ \\
\hline Grass & $5(42)$ & $4(33)$ & $4(33)$ & $5(42)$ \\
\hline Late phase reaction $\left(\mathrm{AUC}_{2-8 \mathrm{~h}} ; \mathrm{mm}^{2} \times \mathrm{h}\right)$ & $4775(9893)$ & $4036(2640)$ & $4590(4874)$ & $4013(2259)$ \\
\hline LPS-induced TNF- $\alpha(\mathrm{ng} / \mathrm{ml})$ & $11.1(4.1)$ & $10.7(4.3)$ & $10.6(3.8)$ & $10.2(3.4)$ \\
\hline Body mass index $\left(\mathrm{kg} / \mathrm{m}^{2}\right)$ & $24.2(1.7)$ & $23.4(2.8)$ & $24.0(2.4)$ & $24.3(2.9)$ \\
\hline Glucose $\left(\mathrm{AUC}_{0-3} ; \mathrm{mg} / \mathrm{dl} \times \mathrm{h}\right)$ & $336.8(49.2)$ & $313.0(39.8)$ & $321.8(28.4)$ & $333.8(43.6)$ \\
\hline Insulin $\left(\mathrm{AUC}_{0-3 \mathrm{~h}} ; \mu \mathrm{lU} / \mathrm{ml} \times \mathrm{h}\right)^{\prime}$ & $103.7(28.4)$ & $86.8(28.1)$ & 106.5 (39.8) & $119.2(61.0)$ \\
\hline C-peptide $\left(\mathrm{AUC}_{0-3 \mathrm{~h}}(\mathrm{ng} / \mathrm{ml} \times \mathrm{h})\right.$ & $19.8(3.5)$ & $17.1(3.5)$ & $19.7(3.8)$ & $21.6(5.9)$ \\
\hline Fasting glucose $(\mathrm{mg} / \mathrm{dl})$ & $79.0(10.4)$ & $78.1(8.3)$ & $78.0(11.1)$ & $80.3(6.9)$ \\
\hline Fasting insulin ( $\mu \mathrm{l} \mathrm{U} / \mathrm{ml})$ & $3.8(3.5)$ & $2.4(3.5)$ & $3.3(2.8)$ & $3.8(7.6)$ \\
\hline Fasting C-peptide (ng/ml) & $1.4(0.7)$ & $1.2(0.7)$ & $1.4(0.7)$ & $1.6(0.7)$ \\
\hline \multicolumn{5}{|l|}{ Bone turnover markers $(8 \mathrm{~h} ; \mathrm{ng} / \mathrm{ml})$} \\
\hline Osteocalcin & $22.8(5.1)$ & $30.5(10.0)$ & $21.9(10.1)$ & $21.5(7.5)$ \\
\hline PINP & $53.5(17.7)$ & $78.4(30.3)$ & $54.4(24.1)$ & $49.3(21.0)$ \\
\hline PICP & $95.3(39.1)$ & $136.7(36.0)$ & $105.4(62.3)$ & $100.1(44.1)$ \\
\hline NTX & $11.5(1.6)$ & $12.4(3.2)$ & $10.0(2.2)$ & $12.6(3.1)$ \\
\hline \multicolumn{5}{|l|}{ Bone turnover markers (24 h; ng/ml) } \\
\hline Osteocalcin & $27.1(5.6)$ & $36.2(11.7)$ & $27.6(12.1)$ & $25.3(8.7)$ \\
\hline PINP & $56.9(19.3)$ & $84.3(33.3)$ & $60.3(26.2)$ & $52.4(20.5)$ \\
\hline PICP & 99.3 (33.9) & $136.8(44.6)$ & 126.4 (73.9) & $106.4(40.9)$ \\
\hline NTX & $15.3(3.8)$ & $17.1(4.7)$ & $11.4(2.5)$ & $15.4(5.5)$ \\
\hline
\end{tabular}

Pred, prednisone. 
dose, ACTH was suppressed at $0800 \mathrm{~h}$ on day 7 compared with placebo $(P=0.019)$ and decreased further in parallel with placebo over the course of the day (Fig. 1).

\section{Anti-inflammatory effects of prednisone}

An established marker of GC activity is change in peripheral WBC count. Consistent with findings from previous reports, changes were observed within $5 \mathrm{~h}$ of treatment on both days 1 and 7 for all doses of prednisone. Neutrophil counts increased, whereas lymphocyte and monocyte counts all decreased significantly in a dose-dependent manner. Eosinophil counts
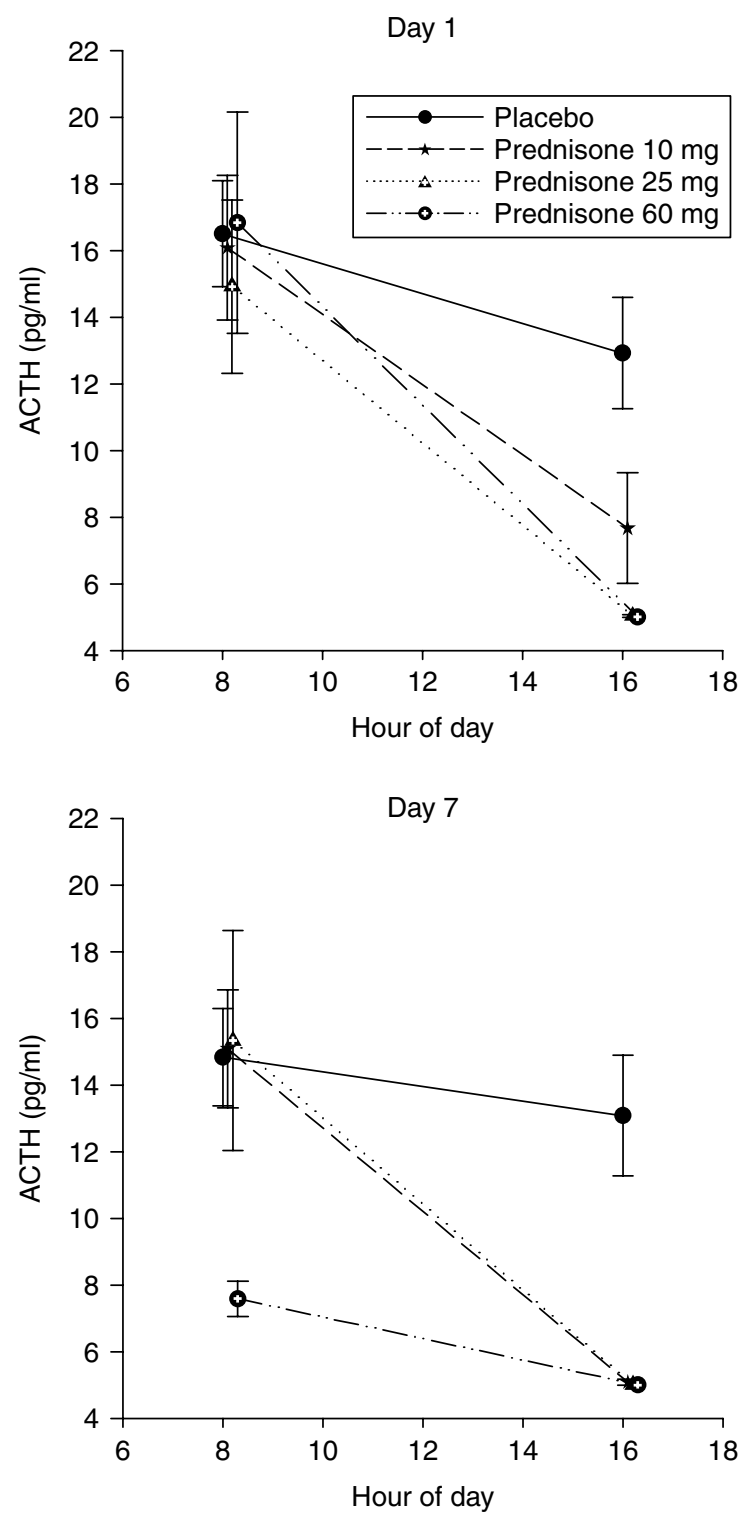

Figure 1 Serum ACTH was measured on days 1 and 7 , just before and $8 \mathrm{~h}$ after treatment. Means \pm S.E.M. are shown. also decreased significantly, but a dose-dependent effect was not seen at the doses of prednisone administered (Supplementary Table 1S, see section on supplementary data given at the end of this article).

Measurement of TNF- $\alpha$ in whole blood stimulated ex vivo with LPS - previously demonstrated to be a sensitive marker of GC anti-inflammatory activity $(19,22)$ - was also performed. TNF- $\alpha$ at $8 \mathrm{~h}$ after prednisone treatment showed significant, dose-responsive reductions on both days 1 and 7 (Fig. 2). Since TNF- $\alpha$ is secreted predominantly by macrophages and monocytes, TNF- $\alpha$ concentrations were also corrected for the observed reduction in peripheral monocytes. However, this correction did not qualitatively change the results.

The $\mathrm{AUC}_{2-8} \mathrm{~h}$ of the LPR to cutaneous allergen challenge, the primary endpoint for the anti-inflammatory effects of prednisone, represented a less sensitive marker of its anti-inflammatory effects. The reduction in area of the LPR was significant compared with placebo on days 1 and 7 for the highest dose of prednisone, $60 \mathrm{mg}$, but not the lower doses (Table 2). Skin biopsy samples taken on day 7 from the site of allergen challenge also showed a significant reduction in eosinophil infiltration to the site of cutaneous allergen challenge for the $60 \mathrm{mg}$ dose but not lower doses (data not shown).

\section{Prednisone effects on glucose tolerance}

For overnight fasted subjects, prednisone treatment increased fasting glucose and insulin concentrations after $5 \mathrm{~h}$ following administration (Table 3). The increases in fasting glucose were comparable for both days 1 and 7 , although the increases in fasting insulin were at least twofold higher on day 7 compared with day 1. Fasting C-peptide was also higher on day 7 compared with day 1 . All prednisone doses resulted in significantly increased insulin resistance compared with placebo, using the homeostatic model assessment of insulin resistance ((HOMA-IR) (23)), Table 3. Furthermore, this impairment appeared to be exacerbated with longer treatment. For the higher prednisone doses of 25 and $60 \mathrm{mg}$, an acute impairment in insulin secretion compared with placebo was observed as assessed on day 1 by HOMA of $\beta$-cell function (\%B, (23) Table 3). These effects appeared to be transient since the differences compared with placebo were not seen on day 7 .

Prednisone treatment decreased glucose tolerance in a dose-dependent manner as indicated by the glycaemic excursion observed during an OGTT, with corresponding increases in serum insulin (Fig. 3). On day 1, increases in $\mathrm{AUC}_{0-3} \mathrm{~h}$ of plasma glucose were significant compared with placebo at all doses of prednisone, including the $10 \mathrm{mg}$ dose (Table 3). Moreover, based on their $2 \mathrm{~h}$ plasma glucose concentration during the OGTT on day 1 , half the subjects receiving $10 \mathrm{mg}$ prednisone met the criteria for impaired glucose tolerance $(6 / 12)$, and all of the subjects receiving 25 or $60 \mathrm{mg}$ met the criteria for either impaired glucose 


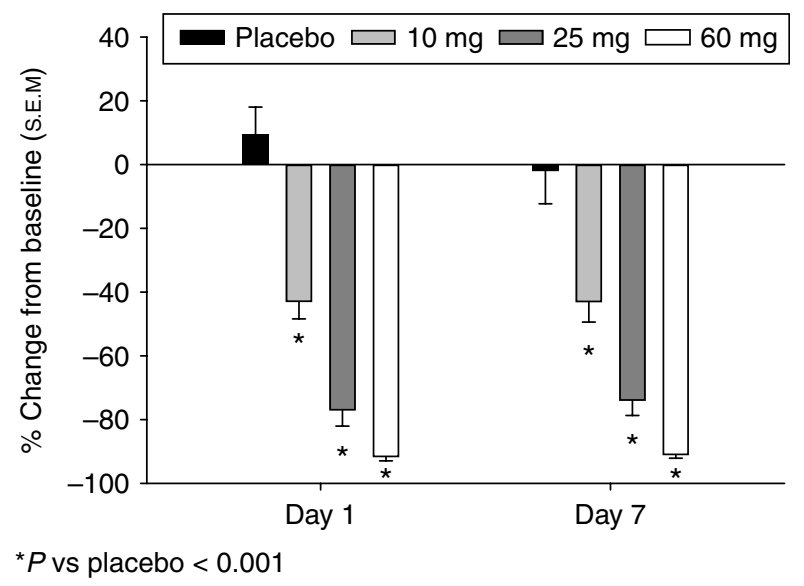

Figure 2 Reductions in TNF- $\alpha$ induced ex vivo by LPS in whole blood acquired $8 \mathrm{~h}$ after treatment $\left({ }^{*} P<0.001\right)$.

tolerance $(25 \mathrm{mg}, 4 / 12 ; 60 \mathrm{mg}, 4 / 12)$ or diabetes ( $25 \mathrm{mg}, 8 / 12 ; 60 \mathrm{mg}, 8 / 12$ ). The increase in $\mathrm{AUC}_{0-3 \mathrm{~h}}$ of plasma glucose was also significant for the 25 and $60 \mathrm{mg}$ doses on day 7. The $\mathrm{AUC}_{\mathrm{O}-3 \mathrm{~h}}$ of insulin and C-peptide increased significantly for the 25 and $60 \mathrm{mg}$ doses on day 7 (Table 3). Of note, the increases were numerically greater on day 7 than day 1 .

\section{Prednisone effects on bone turnover}

Serum concentrations of the bone formation marker osteocalcin were rapidly and significantly reduced by all prednisone doses (Fig. 4). Significant reductions in serum osteocalcin were observed as early as $5 \mathrm{~h}$ after the initial prednisone administration for all doses (data not shown). The effects were dose-dependent, and the differences between prednisone and placebo were significant $(P<0.001)$.

Other markers of bone formation, serum PINP and PICP, also decreased significantly following prednisone administration. For PINP, both 25 and $60 \mathrm{mg}$ doses were associated with significant reduction in serum concentrations on day 1 , whereas all prednisone doses significantly suppressed PINP on day 7 (Fig. 3). In contrast, only the $60 \mathrm{mg}$ prednisone dose reduced PICP on day 1 , while the 25 and $60 \mathrm{mg}$ reduced PICP levels on day 7. Significant increases in a marker of bone resorption, serum NTX, also occurred for the higher prednisone doses. Serum levels of the anti-osteogenic factor Dkk-1 were also examined $24 \mathrm{~h}$ after treatment. There was no discernible effect of prednisone on either day 1 or 7 (data not shown).

\section{Discussion}

The aim of the present study was to evaluate several dose-responsive, anti-inflammatory efficacy biomarkers and to compare the time-course of these dose-dependent, anti-inflammatory changes with those observed for indicators of glucose tolerance and bone metabolism following short-term administration of the widely used GC, prednisone. Prednisone doses were selected to be representative of the therapeutic dose range typically used in clinical practice.

Supraphysiologic GC activity has long been established to suppress the hypothalamic-pituitary-adrenal (HPA) axis. As anticipated, all prednisone doses suppressed serum ACTH compared with placebo acutely. However, following 6 days of dosing, $60 \mathrm{mg}$ prednisone was observed to have more durable HPA inhibitory effects compared with lower doses (i.e. 25 and $10 \mathrm{mg}$ ), as indicated by the suppressed $0800 \mathrm{~h}$ (predose) ACTH on day 7. To our knowledge, these acute dose-dependent differences between supraphysiologic prednisone doses on the HPA axis suppression have not been previously described. Although the exact duration of ACTH suppression for the $60 \mathrm{mg}$ dose is unknown, it raises the possibility that HPA axis suppression should be considered in patients receiving high doses of prednisone ( $\geq 60 \mathrm{mg}$ ) after 6 days.

LPS-stimulated TNF- $\alpha$ release in $e x$ vivo whole blood was shown to be a very sensitive anti-inflammatory efficacy marker for prednisone and was significantly suppressed after both single and multiple doses for all prednisone doses studied. The observed decreases in TNF- $\alpha$ release were dose-dependent. In addition, acute, dose-dependent changes in peripheral WBC count were observed following single and multiple doses of all prednisone doses studied, as shown previously $(24,25,26)$. It is interesting to note that for both LPSstimulated TNF- $\alpha$ release and peripheral WBC count, prednisone-induced effects were near-complete within hours after a single dose, and subsequent doses did not result in additional changes in these biomarkers.

Late-phase reactions at times ranging from 6 to $24 \mathrm{~h}$ following cutaneous allergen challenge have been

\begin{tabular}{|c|c|c|}
\hline Treatment & $\begin{array}{l}\mathbf{L P R}_{\mathbf{A U C} \mathbf{2} 2-8 \mathbf{h}} \\
\quad\left(\mathrm{mm}^{2} \times \mathrm{h}\right)\end{array}$ & $\begin{array}{c}P \text { value } \\
\text { vs placebo* }\end{array}$ \\
\hline \multicolumn{3}{|l|}{ Day 1} \\
\hline $\begin{array}{l}\text { Placebo } \\
\text { Prednisone }\end{array}$ & $29.4(23.2)$ & \\
\hline $10 \mathrm{mg}$ & $-5.9(15.4)$ & 0.890 \\
\hline $25 \mathrm{mg}$ & $-34.1(13.8)$ & 0.084 \\
\hline $60 \mathrm{mg}$ & $-54.6(10.2)$ & $\leq 0.001$ \\
\hline \multicolumn{3}{|l|}{ Day 7} \\
\hline Placebo & $1.6(27.9)$ & \\
\hline \multicolumn{3}{|l|}{ Prednisone } \\
\hline $10 \mathrm{mg}$ & $-22.8(11.2)$ & 0.817 \\
\hline $25 \mathrm{mg}$ & $-29.6(9.5)$ & 0.724 \\
\hline $60 \mathrm{mg}$ & $-51.7(10.6)$ & 0.047 \\
\hline
\end{tabular}


Table 3 Serum markers of glucose tolerance and HOMA values.

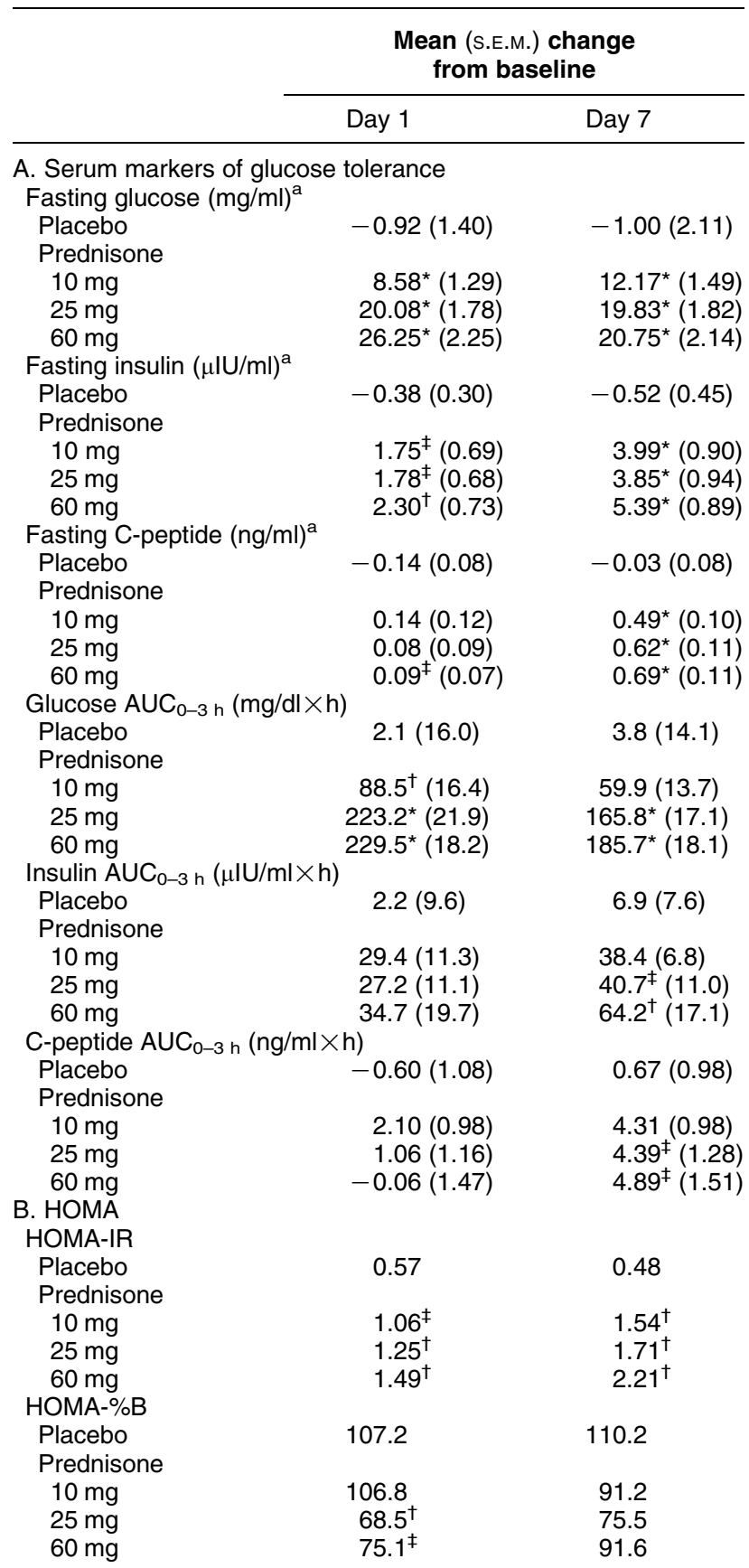

HOMA, homeostatic model assessment, based on fasting glucose and insulin concentrations taken $\sim 5 \mathrm{~h}$ after treatment in overnight fasted subjects and 10 min prior to the OGTT; IR, insulin resistance; $\% \mathrm{~B}, \beta$ cell function; ${ }^{*} P$ vs placebo $\leq 0.001,{ }^{\dagger} P$ vs placebo $<0.01,{ }^{\ddagger} P$ vs placebo $<0.05$.

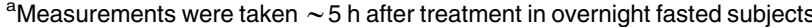
and 10 min prior to the OGTT, after 13-h fast.

previously reported to be significantly reduced by treatment with prednisone at single and multiple doses ranging from 20 to $60 \mathrm{mg}(27,28,29)$. However, it was unknown whether attenuation of the LPR was either dose-responsive or a sensitive biomarker of GC anti-inflammatory effects. In the current study, only the high, $60 \mathrm{mg}$ dose of prednisone was observed to significantly attenuate the size of the LPR compared with placebo. The inability to demonstrate any significant effects on LPR size with lower prednisone doses suggests that the LPR may not be adequately sensitive to assess less potent anti-inflammatory effects. A notable complication was the significant inter-subject variability observed in LPR response, which may have served to obscure detection of the effect, particularly for the lower prednisone doses. A post hoc analysis of the LPR data revealed several parameters which could be optimized to reduce the observed variability. This was undertaken in a follow-up study (to be reported separately) and demonstrated significant reduction in LPR size following a single dose of $20 \mathrm{mg}$ prednisone.

Supraphysiologic GC activity leads to impaired glucose tolerance $(1,2,3)$. It was recently demonstrated that low doses of prednisolone $(7.5 \mathrm{mg})$ administered daily for 2 weeks in healthy men impaired insulin suppression of hepatic glucose production and insulinmediated suppression of lipolysis (30). Thus, it was not surprising that in the current study, single doses of 25 and $60 \mathrm{mg}$ prednisone induced impaired glucose tolerance acutely. However, the results of the current study suggest that a single dose of $10 \mathrm{mg}$ prednisone may also impair glucose tolerance acutely. GC-induced insulin resistance certainly contributed to the glucose intolerance and was evident in the elevated fasting insulin and C-peptide concentrations noted on day 7 compared with day 1 , and consistent with the HOMAIR findings. It should be noted that although all enrolled
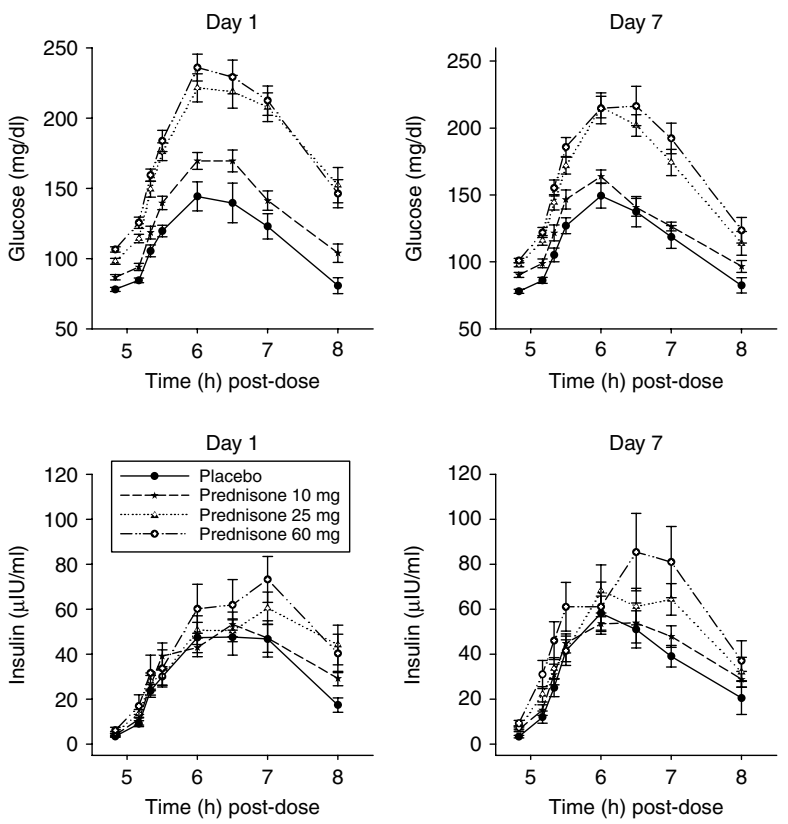

Figure 3 Oral glucose tolerance test. 

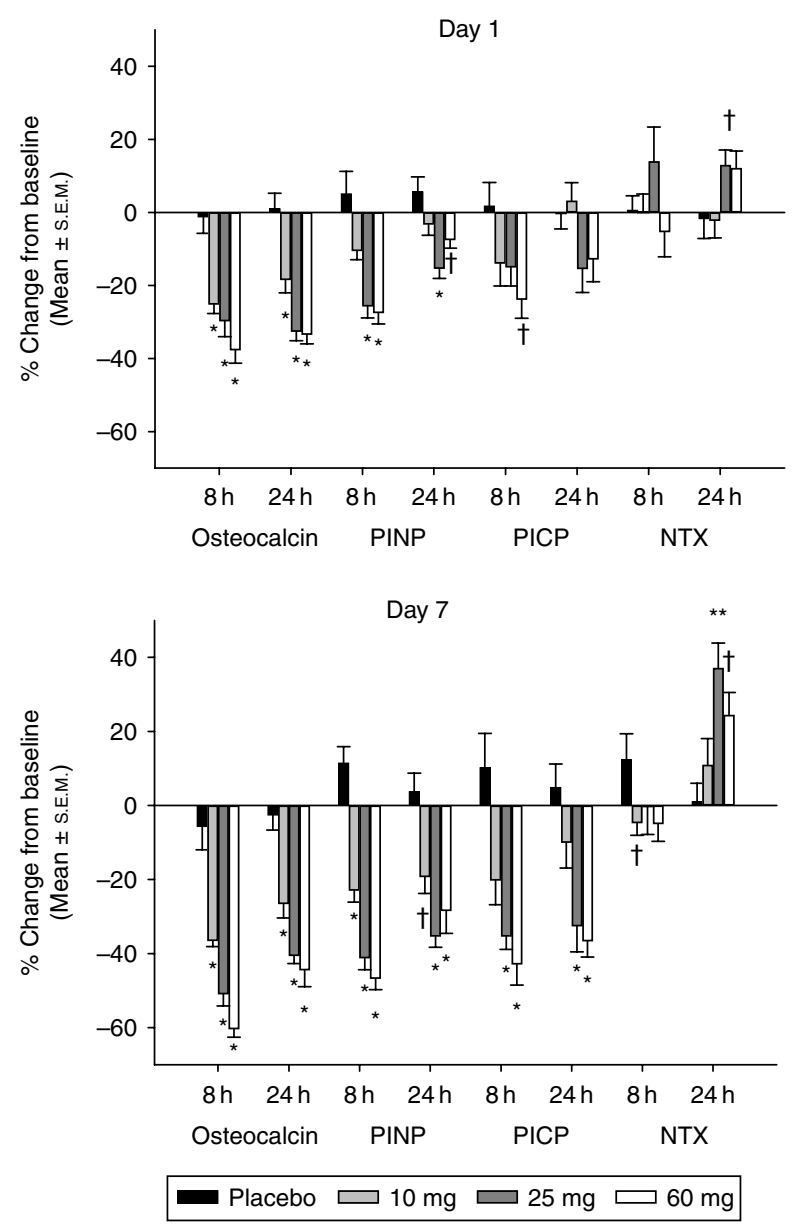

Figure 4 Mean changes from baseline in bone turnover markers ( ${ }^{\star} P$ vs placebo $<0.001,{ }^{\star \star} P$ vs placebo $<0.01,{ }^{\dagger} P$ vs placebo $<0.05$ ).

subjects demonstrated normal glucose tolerance at baseline, they were required to demonstrate hypersensitivity to allergen and had received a cutaneous allergen challenge prior to glucose administration for the OGTT. It is unknown what contribution this hypersensitive state may have had in exacerbating or predisposing to glucose intolerance following even a single prednisone dose. Furthermore, it has been reported that interstitial hyperglycaemia associated with prednisolone treatment is predominantly manifested in the afternoon and evening in patients receiving prednisolone treatment while undergoing continuous glucose monitoring (31). Accordingly, the OGTT was conducted during the mid-late afternoon. However, since subjects had been fasting for $13-16 \mathrm{~h}$, the prolonged fast may also have contributed to augmenting the observed effects. Nonetheless, these results suggest that in susceptible individuals, modest doses of prednisone may impair glucose tolerance acutely. It remains unknown whether the acute impairment of glucose tolerance (i.e. after a single dose) would persist. It is interesting to note that the glycaemic excursion during the OGTT after multiple prednisone doses appeared to diminish over time. Moreover, the insulin and C-peptide excursions during the OGTT were notably higher following multiple doses compared with a single dose, suggesting that the $\beta$-cell response is augmented with repeated prednisone dosing and/or prednisoneinduced hyperglycaemia. This was also consistent with the HOMA-\%B findings.

Certainly, GC-induced osteoporosis is a well-known adverse consequence of chronic GC therapy, and several groups have reported that daily prednisone doses as little as $10 \mathrm{mg}$ or lower result in clinically significant bone loss $(16,32)$. In the present investigation, circulating concentrations of the bone formation marker osteocalcin decreased dramatically within hours of administration of all prednisone doses and remained suppressed for at least $24 \mathrm{~h}$. Of the bone formation markers analysed, osteocalcin was the most sensitive to GC treatment. Changes in osteocalcin were previously shown to reflect GC administration in healthy subjects: osteocalcin decreased during lowdose prednisone $(10 \mathrm{mg})$ administration and returned to baseline 2 days after discontinuation of treatment, suggesting that GC-induced changes in bone formation are reflected accurately by osteocalcin (12). Changes in PINP and PICP were less sensitive than osteocalcin to GC treatment. Although GCs have been reported to affect primarily bone formation, a significant increase in bone resorption, as indicated by increased serum NTX, was observed for higher prednisone doses. Interestingly, these effects on serum NTX were not observed until $24 \mathrm{~h}$ after prednisone administration, suggesting perhaps that these may be secondary or indirect responses. Finally, Dkk-1 has previously been suggested to play a role in GC-induced osteoporosis by interfering with canonical Wnt signaling. In contrast to results from in vitro studies with cultured human osteoblasts (33, 34), however, in this study, Dkk-1 concentrations were found to be unchanged in response to prednisone administration. Possible explanations for these results are that longer prednisone administration may be required to affect Dkk-1 expression or that the GC-induced effects on Dkk-1 occur locally and are not detectable in serum.

In summary, dose-responsive anti-inflammatory efficacy biomarkers were identified following single and multiple prednisone dose administration. The short time-course of these dose-dependent, anti-inflammatory changes was also observed for markers of glucose tolerance and bone metabolism. To our knowledge, this is the first time a comprehensive review of GC effects on inflammation, glucose, and bone has been conducted in the same healthy individuals.

\section{Supplementary data}

This is linked to the online version of the paper at http://dx.doi.org/10. 1530/EJE-11-0751. 


\section{Declaration of interest}

E Kauh, L Mixson, M Malice, J Burke, T Reynders, K Van Dyck, C Beals, E Rosenberg and M Ruddy are employees of Merck Sharp and Dohme Corp. or MSD Europe, a subsidiary of Merck and Co., Inc., and may own stock/stock options in Merck. S Mesens and S Ramael have no conflict of interests to report.

\section{Funding}

This study was sponsored by Merck, Whitehouse Station, NJ, USA.

\section{Acknowledgements}

The authors want to thank Gary Herman and Alice Reicin for their contributions to the study design and for several helpful discussions, as well as Belma Dogdas for her analysis of the cutaneous allergen challenge results. Dr Brian Schapiro performed the quantitative histological analysis of skin biopsy samples. We are also very grateful to Dr Paul Atkins for his insights, suggestions and critical reviews of drafts of this manuscript.

\section{References}

1 Schacke H, Docke WD \& Asadullah K. Mechanisms involved in the side effects of glucocorticoids. Pharmacology $\mathcal{E}$ Therapeutics 200296 23-43. (doi:10.1016/S0163-7258(02)00297-8)

2 Vegiopoulos A \& Herzig S. Glucocorticoids, metabolism and metabolic diseases. Molecular and Cellular Endocrinology 2007 275 43-61. (doi:10.1016/j.mce.2007.05.015)

3 van Raalte DH, Ouwens DM \& Diamant M. Novel insights into glucocorticoid-mediated diabetogenic effects: towards expansion of therapeutic options? European Journal of Clinical Investigation 200939 81-93. (doi:10.1111/j.1365-2362.2008.02067.x)

4 Montori VM, Basu A, Erwin PJ, Velosa JA, Gabriel SE \& Kudva YC. Posttransplantation diabetes: a systematic review of the literature. Diabetes Care 200225 583-592. (doi:10.2337/diacare.25.3.583)

5 Uzu T, Harada T, Sakaguchi M, Kanasaki M, Isshiki K, Araki S, Sugiomoto T, Koya D, Haneda M, Kashiwagi A \& Yamauchi A. Glucocorticoid-induced diabetes mellitus: prevalence and risk factors in primary renal diseases. Nephron. Clinical Practice 2007 105 c54-c57. (doi:10.1159/000097598)

6 Schneiter P \& Tappy L. Kinetics of dexamethasone-induced alterations of glucose metabolism in healthy humans. American Journal of Physiology 1998275 E806-E813.

7 Saag KG. Glucocorticoid-induced osteoporosis. Endocrinology and Metabolism Clinics of North America 200332 135-157, vii. (doi:10.1016/S0889-8529(02)00064-6)

8 De Nijs RN. Glucocorticoid-induced osteoporosis: a review on pathophysiology and treatment options. Minerva Medica 200899 23-43.

9 Berris KK, Repp AL \& Kleerekoper M. Glucocorticoid-induced osteoporosis. Current Opinion in Endocrinology, Diabetes, and Obesity 200714 446-450. (doi:10.1097/MED.0b013e3282f15407)

10 Canalis E, Mazziotti G, Giustina A \& Bilezikian JP. Glucocorticoidinduced osteoporosis: pathophysiology and therapy. Osteoporosis International 200718 1319-1328. (doi:10.1007/s00198-0070394-0)

11 Ton FN, Gunawardene SC, Lee H \& Neer RM. Effects of low-dose prednisone on bone metabolism. Journal of Bone and Mineral Research 200520 464-470. (doi:10.1359/JBMR.041125)

12 Lems WF, Van Veen GJ, Gerrits MI, Jacobs JW, Houben HH, Van Rijn HJ \& Bijlsma JW. Effect of low-dose prednisone (with calcium and calcitriol supplementation) on calcium and bone metabolism in healthy volunteers. British Journal of Rheumatology 199837 27-33. (doi:10.1093/rheumatology/37.1.27)
13 Godschalk MF \& Downs RW. Effect of short-term glucocorticoids on serum osteocalcin in healthy young men. Journal of Bone and Mineral Research 19883 113-115. (doi:10.1002/jbmr. 5650030117)

14 Kuroki Y, Kaji H, Kawano S, Kanda F, Takai Y, Kajikawa M \& Sugimoto T. Short-term effects of glucocorticoid therapy on biochemical markers of bone metabolism in Japanese patients: a prospective study. Journal of Bone and Mineral Metabolism 2008 26 271-278. (doi:10.1007/s00774-007-0821-5)

15 Gram J, Junker P, Nielsen HK \& Bollerslev J. Effects of short-term treatment with prednisolone and calcitriol on bone and mineral metabolism in normal men. Bone 199823 297-302. (doi:10. 1016/S8756-3282(98)00097-0)

16 van Staa TP, Leufkens HG \& Cooper C. The epidemiology of corticosteroid-induced osteoporosis: a meta-analysis. Osteoporosis International 200213 777-787. (doi:10.1007/s001980200108)

17 van Staa TP. The pathogenesis, epidemiology and management of glucocorticoid-induced osteoporosis. Calcified Tissue International 200679 129-137. (doi:10.1007/s00223-006-0019-1)

18 Schacke H, Berger M, Rehwinkel H \& Asadullah K. Selective glucocorticoid receptor agonists (SEGRAs): novel ligands with an improved therapeutic index. Molecular and Cellular Endocrinology 2007275 109-117. (doi:10.1016/j.mce.2007.05.014)

19 Brideau C, Van Staden C, Styhler A, Rodger IW \& Chan CC. The effects of phosphodiesterase type 4 inhibitors on tumour necrosis factor-alpha and leukotriene B4 in a novel human whole blood assay. British Journal of Pharmacology 1999126 979-988. (doi:10.1038/sj.bjp.0702387)

20 Pacini G \& Mari A. Methods for clinical assessment of insulin sensitivity and beta-cell function. Best Practice $\&$ Research. Clinical Endocrinology \& Metabolism 200317 305-322. (doi:10.1016/ S1521-690X(03)00042-3)

21 Mari A, Pacini G, Murphy E, Ludvik B \& Nolan JJ. A model-based method for assessing insulin sensitivity from the oral glucose tolerance test. Diabetes Care 200124 539-548. (doi:10.2337/ diacare.24.3.539)

22 Waage A \& Bakke O. Glucocorticoids suppress the production of tumour necrosis factor by lipopolysaccharide-stimulated human monocytes. Immunology 198863 299-302.

23 Wallace TM, Levy JC \& Matthews DR. Use and abuse of HOMA modeling. Diabetes Care 200427 1487-1495. (doi:10.2337/ diacare.27.6.1487)

24 Cameron RG, Black PN, Braan C \& Browett PJ. A comparison of the effects of oral prednisone and inhaled beclomethasone dipropionate on circulating leukocytes. Australian and New Zealand Journal of Medicine 199626 800-805. (doi:10.1111/j.14455994.1996.tb00628.x)

25 Oehling AG, Akdis CA, Schapowal A, Blaser K, Schmitz M \& Simon HU. Suppression of the immune system by oral glucocorticoid therapy in bronchial asthma. Allergy 199752 144-154. (doi:10.1111/j.1398-9995.1997.tb00968.x)

26 Serra-Bonett N, Al Snih S \& Rodriguez MA. Effect of low-dose prednisone on leukocyte counts and subpopulations in patients with rheumatoid arthritis. Journal of Clinical Rheumatology 2009 15 148-149. (doi:10.1097/RHU.0b013e3181a3ac2d)

27 Charlesworth EN, Kagey-Sobotka A, Schleimer RP, Norman PS \& Lichtenstein LM. Prednisone inhibits the appearance of inflammatory mediators and the influx of eosinophils and basophils associated with the cutaneous late-phase response to allergen. Journal of Immunology $1991 \mathbf{1 4 6} 671-676$.

28 Varney V, Gaga M, Frew AJ, De Vos C \& Kay AB. The effect of a single oral dose of prednisolone or cetirizine on inflammatory cells infiltrating allergen-induced cutaneous late-phase reactions in atopic subjects. Clinical and Experimental Allergy 199222 43-49. (doi:10.1111/j.1365-2222.1992.tb00113.x)

29 Taborda-Barata L, Jacobson M, Walker S, Njuki F, Ying S, Randev P, Durham SR \& Kay AB. Effect of cetirizine and prednisolone on cellular infiltration and cytokine mRNA expression during allergen-induced late cutaneous responses. Clinical and Experimental Allergy 199626 68-78. (doi:10.1111/j. 1365-2222.1996.tb00058.x) 
30 van Raalte DH, Brands $\mathrm{M}$, van der Zijl NJ, Muskiet $\mathrm{MH}$, Pouwels PJW, Ackermans MT, Sauerwein HP, Serlie MJ \& Diamant M. Low-dose glucocorticoid treatment affects multiple aspects of intermediary metabolism in healthy humans: a randomised controlled trial. Diabetologia 201154 2103-2112. (doi:10.1007/s00125-011-2174-9)

31 Burt MG, Roberts GW, Aguilar-Loza NR, Frith P \& Stranks SN. Continuous monitoring of circadian glycemic patterns in patients receiving prednisolone for COPD. Journal of Clinical Endocrinology and Metabolism 201196 1789-1796. (doi:10.1210/jc.20102729)

32 Civitelli R \& Ziambaras K. Epidemiology of glucocorticoid-induced osteoporosis. Journal of Endocrinological Investigation 200831 (7 Suppl) 2-6.
33 Ohnaka K, Tanabe M, Kawate H, Nawata H \& Takayanagi R. Glucocorticoid suppresses the canonical Wnt signal in cultured human osteoblasts. Biochemical and Biophysical Research Communications 2005329 177-181. (doi:10.1016/j.bbrc.2005.01.117)

34 Ohnaka K, Taniguchi H, Kawate H, Nawata H \& Takayanagi R. Glucocorticoid enhances the expression of dickkopf- 1 in human osteoblasts: novel mechanism of glucocorticoid-induced osteoporosis. Biochemical and Biophysical Research Communications 2004 318 259-264. (doi:10.1016/j.bbrc.2004.04.025)

Received 25 August 2011

Revised version received 18 November 2011

Accepted 16 December 2011 